\title{
A method to select between periodic cointegration and seasonal cointegration
}

\author{
Philip Hans Franses \\ Econometric Institute, Erasmus University, P.O. Box 1738, NL-3000 DR Rotterdam, Netherlands \\ Received 16 March 1992 \\ Accepted 16 December 1992
}

\begin{abstract}
The seasonal and the periodic cointegration models are non-nested models that can cxplain complex patterns in univariate seasonal time series. This paper proposes a simple model selection method which is based on an application of the usual test procedures for cointegration to the annual series per season.
\end{abstract}

\section{Introduction}

Recently, there has been some attention given to the seasonal fluctuations in seasonally observed time series. Although the results of several studies depend on the particular method used, a general impression from the empirical evidence is that seasonal patterns in many economic time series are more complicated than those justifying the use of seasonal dummies. Using the test procedure for seasonal unit roots of Hylleberg ct al. (1990) [HEGY], Hylleberg et al. (1991) find that several economic series have seasonal unit roots. On the other hand, using a periodic generalization of the HEGY method, Franses and Romijn (1992) find that many U.K. macroeconomic variables show patterns which are typical for periodically integrated series; see also Osborn and Smith (1989).

Multivariate extensions of the seasonal and periodic integration concepts are discussed in, for example, Engle et al. (1991), and in Birchenhall et al. (1989) and Franses and Kloek (1991), respectively. The seasonal cointegration model in Engle et al. (1991), and also in Kunst (1990), focuses on two or more series having common non-stationary seasonal components. The periodic cointegration model assumes that the parameters in the cointegration vectors, as well as the adjustment parameters, can vary over the seasons. Given the different outcomes of the analyses of univariate time series, one can imagine that the non-nested seasonal and periodic cointegration models can be rival dynamic econometric models. A method to select between these two alternatives may therefore be useful. The proposal of such a method is the topic of the present paper.

In section 2 I briefly review some of the characteristics of the seasonal and periodic cointegration models. In section 3 I propose a model selection method, which amounts to considering often applied test statistics for cointegration for the annual series of the observation per quarter. Section 4 concludes the paper. 


\section{Seasonal cointegration and periodic cointegration}

Consider two quarterly observed time series, $x_{t}$ and $y_{t}, t=1, \ldots, n$. In the case when these variables are non-stationary, it can be useful to transform these series with a $\Delta_{1}$ or a $\Delta_{4}$ filter, where $\Delta_{k}$ is defined $\Delta_{k} z_{t}=\left(1-B^{k}\right) z_{t}=z_{t}-z_{t-k}$. When the first filter is appropriate, one says that the series has a non-seasonal unit root 1 . When the $\Delta_{4}$ filter is appropriate, the series additionally has seasonal unit roots -1 and $\pm i$ since $\left(1-B^{4}\right)=(1-B)(1+B)(1-i B)(1+i B)$. A test procedure to test for seasonal unit roots is given in Hylleberg et al. (1990).

Suppose now that both series $x_{t}$ and $y_{t}$ are seasonally integrated, or that $\Delta_{4} x_{t}$ and $\Delta_{4} y_{t}$ are stationary. These series are then said to be seasonally cointegrated when they have common seasonally non-stationary components, see Engle et al. (1991) [EGHL]. When there is cointegration at the zero frequency, i.e. related to root 1 , this means that $u_{t}$, defined by

$$
u_{t}=\left(1+B+B^{2}+B^{3}\right) x_{t}-\alpha_{1}\left(1+B+B^{2}+B^{3}\right) y_{t},
$$

is stationary. This is because $(1-B)^{4}$ cquals $(1 \quad B)\left(1+B+B^{2}+B^{3}\right)$. Cointegration at frequency $\frac{1}{2}$, i.e. with respect to root -1 , implies that

$$
v_{t}=\left(1-B+B^{2}-B^{3}\right) x_{t}-\alpha_{2}\left(1-B+B^{2}-B^{3}\right) y_{t}
$$

is stationary. Finally, cointegration at frequency $\frac{1}{4}$ is related to the filter $\left(1-B^{2}\right)$. Since this filter only covers a half-year period, one should also consider cointegration one period lagged, or

$$
w_{t}=\left(1-B^{2}\right) x_{t}-\alpha_{3}\left(1-B^{2}\right) y_{t}-\alpha_{4}\left(1-B^{2}\right) x_{t-1}-\alpha_{5}\left(1-B^{2}\right) y_{t-1}
$$

is stationary. Test procedures for the stationarity of the variables in (1), (2) and (3) are discussed in EGHL. The first equation of the general seasonal cointegration model is

$$
\phi_{p}(B) \Delta_{4} x_{t}=\theta_{q}(B) \Delta_{4} y_{t}+\gamma_{1} u_{t-1}+\gamma_{2} v_{t-1}+\gamma_{3} w_{t-2}+\gamma_{4} w_{t-3}+\epsilon_{t},
$$

where the $\phi_{p}(B)$ and $\theta_{q}(B)$ are polynomials in $B$. The variables $u_{t}, v_{t}$ and $w$, are the errorcorrecting variables. The $\epsilon_{t}$ denotes an uncorrelated zero mean process with constant variance.

The periodic cointegration model is an alternative extension of the usual cointegration concept. This model considers an error-correction model in which the parameters are allowed to vary over the seasons, or

$$
\phi_{p}(B) \Delta_{4} x_{t}=\theta_{q}(B) \Delta_{4} t_{t}+\sum_{s=1}^{4} \beta_{s} D_{s t}\left(x-\mu_{s}-\phi_{s} y\right)_{t-k}+\epsilon_{t},
$$

where the $D_{s t}$ denote the seasonal dummies. A specification strategy for this model is proposed in Franses and Kloek (1991). From (5) it is clear that there are varying cointegration relations per quarter, and also that adjustment to disequilibrium errors can be time-varying.

\section{Model selection}

The models, as given in (4) and (5), are obviously non-nested. One way to select between these models may then be to construct an encompassing model and to test the parameter restrictions in this large model that are implied by each of the two models. Given that the series $x_{t}$ and $y_{t}$ are non-stationary, the $F$-type tests do not follow standard distributions under either one of the null 
hypotheses. Furthermore, these distributions may depend on the parameter values $\alpha_{i}$ and the $\mu_{s}$ and $\phi_{s}$.

There is, however, a simple way to circumvent these problems, and this is by considering the usual cointegration test statistics for the annual series containing the observations per quarter. This is easily seen by focusing on the differences between the seasonal and periodic cointegration models, which are best explored by considering a vector of quarters representation for a bivariate time series; see Franses (1991). Suppose that we decompose the $x_{t}$ series into four annual series $x_{s, T}$, where $T=1, \ldots, N$ is an annual index, containing the observations per season $s$, and similarly the $y_{t}$ series into four $y_{s . T}$ 's. Furthermore, suppose that we are considering possible cointegrating relationships between the eight elements of $\left\{x_{s, T}, y_{s, T}\right\}$. The periodic cointegration model assumes that the elements in corresponding seasons are cointegrated. Seasonal cointegration, however, does not assume such relations. For example, from (1)-(3) it can be seen that in each occasion there is only one cointegration relation, and that it only holds for a linear function of linear combinations of elements in $x_{s, T}$ and in $y_{s, T}$. Hence, the variables $q_{s, T}=x_{s, T}-m_{s}-f_{s} y_{s, T}$, where $m_{s}$ and $f_{s}$ are obtained by OLS regression, are not stationary. A simple model selection method is now given by four tests for the stationarity of these $q_{s, T}$. Such tests can be given by the cointegrating Durbin-Watson and the Dickey-Fuller test (CRDW and DF). Critical values for these test statistics for $n=100$ are displayed in Franses and Kloek (1991). In case of stationary $q_{s, T}$, the periodic cointegration model can be appropriate, but the seasonal cointegration model is not. In the case of non-stationarity, the periodic model in (5) cannot be valid, while the seasonal cointegration model may be adequate. Note that the parameters $m_{s}$ and $f_{s}$ do not have to be different.

To evaluate the use of the CRDW and DF statistics, consider the results of an illustrative Monte Carlo experiment, displayed in Table 1. This table reports on the frequency of rejection of the null hypotheses of no cointegration between the annual series per quarter when a seasonal cointegration model is the data-generating process. This frequency is in fact the frequency of incorrectly considering a periodic cointegration model. From the empirical rejection frequencies in

Table 1

Empirical rejection frequencies of the null hypothesis of no cointegration between the quarters of $x$, and $y$, in the case when a seasonal cointegration model is the data-generating process ${ }^{2}$

\begin{tabular}{|c|c|c|c|c|c|}
\hline \multirow[t]{2}{*}{ DGP $^{b}$} & \multirow[t]{2}{*}{ Method $^{\mathrm{c}}$} & \multicolumn{4}{|c|}{ Nominal size } \\
\hline & & 0.20 & 0.10 & 0.05 & 0.01 \\
\hline \multirow[t]{2}{*}{ (i) } & CRDW & 0.213 & 0.110 & 0.061 & 0.012 \\
\hline & ADF & 0.198 & 0.103 & 0.057 & 0.014 \\
\hline \multirow[t]{2}{*}{ (ii) } & CRDW & 0.205 & 0.109 & 0.056 & 0.010 \\
\hline & $\mathrm{ADF}$ & 0.203 & 0.101 & 0.055 & 0.014 \\
\hline \multirow[t]{2}{*}{ (iii) } & CRDW & 0.745 & 0.630 & 0.529 & 0.302 \\
\hline & ADF & 0.326 & 0.193 & 0.116 & 0.037 \\
\hline
\end{tabular}

\footnotetext{
${ }^{a}$ The rejection frequencies are based on 20,000 replications of samples of size 100 .

${ }^{\mathrm{b}}$ The data generating process (DGP) is the seasonal cointegration model in (4), where the variables $u_{t}, v_{t}$ and $w_{t}$ are given by (1), (2) and (3). DGP (i) is (4) with $\gamma_{1}=-0.5, \gamma_{2}=\gamma_{3}=\gamma_{4}=0$, and (1) with $\alpha_{1}=1$; DGP (ii) is (4) with $\gamma_{1}=\gamma_{3}=\gamma_{4}=0, \gamma_{2}=-0.5$, and $\alpha_{2}=1$; and DGP (iii) is (4) with $\gamma_{1}=\gamma_{2}=0, \gamma_{3}=\gamma_{4}=-0.25$, and $\alpha_{3}=\alpha_{4}=1, \alpha_{5}=-1$. The $\epsilon_{1}$ are drawn from the standard normal distribution.

" The CRDW and ADF refer to the Durbin-Watson and augmented Dickey-Fuller (one additional lag) statistics for the residuals of the regression of $x_{s, T}$ on a constant and $y_{s, T}, s=1, \ldots, 4$. Critical values of these statistics are given in Franses and Kloek (1991).
} 
Table 1 it can be seen that this simple selection method meets its purpose rather well in the case of seasonal cointegration at the frequencies 0 and $\frac{1}{2}$, i.e. the empirical size is quite close to the nominal size. In the case of seasonal cointegration at frequency $\frac{1}{4}$, the discriminatory power is not as high. This may be explained by the inclusion of $w_{t-2}$ as well as $w_{t-3}$ in (4), which establishes that there are more relationships between the quarters $x_{s, T}$ and $y_{s, T}$. For similar reasons it can be expected that a fully specified seasonal cointegration model as in (4), i.e. when no adjustment parameters are set equal to zero, also may yield a lower discriminatory power. Finally, it emerges that in these cases the augmented DF test may perform better than the CRDW test.

\section{Conclusion}

This paper proposes a model selection method to distinguish a seasonal cointegration model from a periodic cointegration model. It is based on checking with the familiar Durbin-Watson and Dickey-Fuller tests whether the residuals of cointegrating regressions per season are stationary. A limited simulation exercise illustrates the merits of this method. Since the proposed selection device only yields indications of the possible presence of (seasonal) periodic cointegration, it seems appropriate to use it as a first and preliminary check before proceeding with the specification of either of the models.

\section{References}

Birchenhall, C.R., R.C. Bladen-Hovell, A.P.L. Chui, D.R. Osborn and J.P. Smith, 1989, A seasonal model of consumption, Economic Journal 99, 837-843.

Engle, R.F., C.W.J. Granger, S. Hylleberg and H.S. Lee, 1991, Seasonal cointegration: The Japanese consumption function, Journal of Econometrics (forthcoming).

Franses, P.H., 1991, A vector of quarters representation of bivariate time series, Econometric Institute Report 9127.

Franses, P.H. and T. Kloek, 1991, A periodic cointegration model of consumption in Austria and Japan, Econometric Institute Report 9172.

Franses, P.H. and G. Romijn, 1992, Periodicity in quarterly UK macroecononic variables, Unpublished manuscript.

Hylleberg, S., R.F. Engle, C.W.J. Granger and B.S. Yoo, 1990, Seasonal integration and cointegration, Journal of Econometrics 44, 215-238.

Hylleberg, S., C. Jorgensen and N.K. Sorensen, 1991, Seasonality in macroeconomic time series, Unpublished paper, University of Aarhus.

Kunst, R.M. 1990, Seasonal cointegration in macroeconomic systems: Case studies for small and large European countries, Research Memorandum 271.

Osborn, D.R. and J.P. Smith, 1989, The performance of periodic autoregressive models in forecasting seasonal UK consumption, Journal of Business \& Economic Statistics 7, 117-127. 